\title{
Stability Indicating HPTLC Determination of Triamcinalone Acetonide in Bulk Drug and Sterile Injectable Suspension
}

\author{
Girish Pai Kulyadi² \& Muddukrishna Badamane Sathyanarayana ${ }^{*}$ \\ 'Department of Pharmaceutical Quality Assurance, Manipal College of Pharmaceutical Sciences,Manipal-576104, Karnataka, INDIA. \\ 2Department of Pharmaceutics, Manipal College of Pharmaceutical Sciences, Manipal-576104, Karnataka, INDIA.
}

\begin{abstract}
A sensitive, accurate, precise and stability indicating high-performance thin layer chromatographic method was developed and validated for analysis of triamcinalone acetonide (TRIA) in bulk drug and sterile injectable suspension. The method employed HPTLC aluminum precoated plates with silica gel 60F-254 as the stationary phase. The solvent system consisted of Toluene: ethyl acetate: ammonia solution (33:67:0.1 \% v/v). This system was found to give compact bands for TRIA ( $R_{f}$ value $0.38 \pm 0.02$ ). TRIA was subjected to acid, alkali and neutral hydrolysis, oxidation, sun light and dry heat treatment. The degraded products were well separated from the pure drug with notably different $R_{f}$ values. CAMAG semi-automatic HPTLC used for the analysis. Densitometric analysis of TRIA was carried out in the absorbance mode at $240 \mathrm{~nm}$. The linear regression data for the calibration plots showed good linear relationship with correlation coefficient $0.9996 \pm /$ 0.001 in the concentration range of $100.0-2000.0 \mathrm{ng} \mathrm{spot}^{-1}$. The values of slope and intercept were 9.7841 and -86.13 respectively. The method was
\end{abstract}

validated for precision, accuracy, robustness, and recovery. The limits of detection and quantitation were 33.0 and $100.0 \mathrm{ng} \mathrm{spot}^{-1}$ respectively. As the method could effectively separate the drug from its degradation products, it can be employed as a routine stability indicating assay method. Key words: Triamcinalone Acetonide (TRIA), HPTLC, Stability indicating assay method, Degradation, ICH, Validation.

\section{Correspondence:}

Muddukrishna Badamane Sathyanarayana,

Department of Pharmaceutical Quality Assurance,

Manipal College Of Pharmaceutical Sciences,

Manipal-576104, Karnataka, INDIA.

Phone no: +919483932250

E-mail: krishna.mbs@manipal.edu

DOI : 10.5530/jyp.2016.4.20

\section{INTRODUCTION}

Triamcinolone acetonide is a more potent form of triamcinolone, and is used in the post operative period of certain cosmetic surgery procedure. It can be occasionally used to treat severe cases of hay fever.

Chemically, TRIA is 9-Fluoro-11,16,17-trihydroxy-17-(2-hydroxyacetyl)10,13-dimethyl-6,7,8,9,10,11,12,13,14,15,16,17 dodeca hydro cyclopental [a]phenanthren-3-one (Figure 1) with a molecular weight of 394.434 $\mathrm{g} / \mathrm{mol}$.

To our knowledge, no article related to the stability indicating HPTLC densitometry determination of TRIA in bulk drugs and pharmaceutical dosage form has been reported in literature.

The International Conference on Harmonization (ICH) guideline entitled "Stability testing of new drug substances and products" requires that stress testing be carried out to elucidate the inherent stability characteristics of the active substance. ${ }^{1}$ An ideal stability-indicating method is one that quantifies the standard drug alone and also resolves its degradation products. Consequently, the implementation of an analytic methodology to determine TRIA in pharmaceutical dosage form in presence of its degradation products is a pending challenge of the pharmaceutical analysis. Therefore, it was thought necessary to study the stability of TRIA towards acidic, alkaline, oxidative, UV and sunlight degradation processes. The aim of this work was to develop stability-indicating chromatographic methods for determination of TRIA in presence of its degradation products for assessment of purity of bulk drug and stability of its dosage forms by HPTLC densitometry. Over the past decade, high performance thin layer chromatography (HPTLC) has been successfully used in the analysis of pharmaceuticals, plant constituents and bio macromolecules. ${ }^{2-6}$ Forced degradation studies can be useful in the investigation of chemical and physical stability of the crystal form .?

The method is simple, accurate, specific, reproducible, stability indicating. It has added advantage of short duration of the analysis and suitable for routine determination of TRIA in bulk drug and in formulations.

The proposed method was validated in compliance with ICH guidelines, ${ }^{8,9}$ and its updated international convention. ${ }^{10}$

\section{Experimental \\ Materials}

TRIA bulk drug and its injectable suspension were given by Star drugs and research laboratories, Bangalore as a gift sample. Ethyl acetate, Toluene, methanol and ammonia solution (Qualigens Fine Chemicals, Mumbai) used were of analytical grade, CAMAG linomat IV sample applicator equipped with $100 \mu \mathrm{l}$ Hamilton (USA) syringe, CAMAG twin trough glass chamber, CAMAG TLC scanner III densitometer, Cats 3 software.

\section{HPTLC instrumentation}

The samples were applied in the form of bands on the plate, width $6 \mathrm{~mm}$, and $10 \mathrm{~mm}$ from the bottom of the edge using a Merck precoated silica gel aluminium plate $60 \mathrm{~F}-254(20 \times 10 \mathrm{~cm}$ with $0.2 \mathrm{~mm}$ thickness, E.Merck, Germany) with Linomat IV (Switzerland) sample applicator equipped with a $100 \mu \mathrm{L}$ Hamilton (USA) syringe. A constant application rate of $100 \mathrm{~nL} / \mathrm{s}$ was employed and the standard, sample volume was $10 \mu \mathrm{L}$, the space between two bands were $7 \mathrm{~mm}$ and slit dimension was kept $5 \times 0.45 \mathrm{~mm}$ micro and $5 \mathrm{~mm} \mathrm{sec}{ }^{-1}$ scanning speed was employed. The eluting solvent was consisted of Toluene: ethyl acetate: ammonia solution (33:67:0.1 \% v/v). Linear ascending development was carried out in twin trough glass chamber (CAMAG) saturated with mobile phase. Previously the glass chamber was saturated with the help of filter paper and the optimized chamber saturation time was found to be $30 \mathrm{~min}$ at room temperature. The length of chromatogram run was approximately $80 \mathrm{~mm}$. After the development the plates were dried in air with the help of an air-dryer. Densitometric scanning was performed on CAMAG TLC scanner III in the absorbance mode at $240 \mathrm{~nm}$ with 
CATS3 software. The source of radiation utilized was a deuterium lamp. The slit dimensions were $5 \mathrm{~mm} \times 0.45 \mathrm{~mm}$ micro and the scanning speed was $5 \mathrm{~mm} \mathrm{sec}^{-1}$.

\section{Stock Preparation \\ Preparation of stock solution}

Stock solution of $1 \mathrm{mg} / \mathrm{ml}$ was prepared by dissolving $10 \mathrm{mg}$ of TRIA in $10 \mathrm{ml}$ of methanol. From this 10.0, 20.0, 35.0, 80.0, 100.0, 120.0, 125.0 and $200.0 \mu \mathrm{g} \mathrm{mL}^{-1}$ solutions were prepared in methanol. $10.0 \mu \mathrm{L}$ of each of this solution were spotted on the HPTLC plate to obtain concentrations of 100.0, 200.0, 350.0, 800.0, 1000.0, 1200.0, 1250.0 and $2000.0 \mathrm{ng}$ spot $^{-1}$ of TRIA respectively.

\section{Method validation \\ Calibration curve of TRIA}

The working standard solution (mentioned in section 2.3.1) each of $10 \mu \mathrm{L}$ were applied on HPTLC plate to obtain concentration of 100.0, 200.0, 350.0, 800.0, 1000.0, 1200.0, 1250.0 and $2000.0 \mathrm{ng} \mathrm{spot}^{-1}$ of TRIA. The curve was plotted using peak area against the drug concentrations and the data was treated by the linear least square regression. The range was chosen based on the maximum concentration to be kept for the stress studies.

\section{Accuracy and precision of the assay}

\section{Precision}

Repeatability of sample application and measurement of peak areas were carried out using six replicates of the same spot (1000 ng spot ${ }^{-1}$ of TRIA). The intra-day and inter-day variation for the determination of TRIA was carried out at a concentration of $1000 \mathrm{ng}$ spot $^{-1}$.

\section{Accuracy}

The analysed samples were spiked with extra $80,100,120 \%$ of the standard TRIA and the mixture were analysed by the proposed method. At each level of the above said amount, three determinations were performed. This was done to check the recovery of the drug at different levels in the formulations. Recovery was calculated using the following standard formula Recovery [\%] $=[$ (Total conc. - Formulation conc. $) /$ Standard conc.] $\times 100$.

\section{Repeatability}

\section{Repeatability of measurement of peak area}

TRIA (1000 ng/spot) of $10 \mu \mathrm{L}$ was spotted on a HPTLC plate, developed, dried and the spot was scanned seven times without changing the plate position and \% RSD for measurement of peak areas were estimated.

\section{Repeatability of measurement of sample applications}

The drug solution, TRIA, $100 \mu \mathrm{L}$ (1000 ng/spot) was spotted six times on a HPTLC plate, developed and dried. The spots were scanned and \%RSD for measurement of peak areas was estimated.

\section{Robustness}

By introducing small changes in the mobile phase composition, the effects on the results were examined. Mobile phases having different composition of Toluene: ethyl acetate: ammonia solution (31:69:0.1 and 35:65:0.1 v/v) were tried and chromatograms were run. The mobile phase composition, chamber saturation time and temperature for activation of plate were tried in the varied range $\left(25\right.$ and $30 \mathrm{~min}$ at $100^{\circ} \mathrm{C}$ and $120^{\circ} \mathrm{C}$ respectively). Robustness of the method was done at a concentration level of $1000 \mathrm{ng} \mathrm{spot}^{-1}$.

\section{Limit of detection and limit of quantification}

In order to estimate the limit of detection (LOD) and limit of quantitation (LOQ), blank methanol was spotted six times following the same method as explained in Section 2.2. The signal-to-noise ratio was determined. LOD was considered as 3:1 and LOQ as 10:1.

\section{Specificity}

The specificity of the method was ascertained by analyzing standard drug with sample. The spot for TRIA in sample was confirmed by comparing the $R_{\mathrm{f}}$ values and spectra of the spot with that of standard. The peak purity of TRIA was assessed by comparing the spectra at three different levels, i.e., peak start (S), peak apex (M) and peak end (E) positions of the spot.

\section{Analysis of TRIA in prepared formulation}

To determine the concentration of TRIA in sterile injectable suspension (labeled claim: $40 \mathrm{mg} \mathrm{mL}^{-1}$ ), $250 \mu \mathrm{L}$ (10 mg) of TRIA injectable suspension was pipetted out and transferred into three $10 \mathrm{~mL}$ volumetric flasks. $5.0 \mathrm{~mL}$ of methanol was added into each of the flasks, sonicated to dissolve the contents and then the volume was finally made up with methanol. Further this solution was diluted appropriately using methanol to obtain a concentration of $100.0 \mu \mathrm{g} / \mathrm{mL}$. From this solution $10 \mu \mathrm{L}$ (1000 ng spot $^{-1}$ ) was applied on HPTLC plate followed by development and scanning as described in section 2.2. The analysis was repeated in triplicate. The possibility of interferences from excipients in the analysis was studied.

\section{Forced degradation of TRIA}

All stress degradation studies were performed at initial concentration of $100 \mu \mathrm{g} \mathrm{mL} \mathrm{mL}^{-1}$. For these studies, $10 \mathrm{mg}$ of TRIA was accurately weighed and transferred to a $100 \mathrm{~mL}$ volumetric flask (step one).

\section{Acid and base induced degradation}

To the step one, $1 \mathrm{~mL}$ of each $0.01 \mathrm{~N} \mathrm{NaOH}$ (for Alkaline degradation), $0.1 \mathrm{~N} \mathrm{HCl}$ (for Acid degradation), ) were added to separate volumetric flasks and dissolved the content and diluted with methanol to make up the volume and prepared solutions were placed at room temperature for $2 \mathrm{hrs}$ for alkaline degradation and then refluxed at $80^{\circ} \mathrm{C}$ for $8 \mathrm{hrs}$ for acid degradation.

The mixtures were allowed to cool and $1.0 \mathrm{~mL}$ of these solutions were then transferred to a $10 \mathrm{~mL}$ volumetric flasks neutralized with $1.0 \mathrm{~mL}$ of $1 \mathrm{~N} \mathrm{NaOH}$ for acid and neutralized with $1.0 \mathrm{~mL}$ of $1 \mathrm{~N} \mathrm{HCl}$ for alkaline degradation and the volumes were made up with methanol. From this solution $2 \times 50 \mu \mathrm{L}$ samples were plotted in the form of bands by using Linomat IV, Switzerland applicator on precoated silica gel aluminium plate $60 \mathrm{GF}-254$ to get $1000 \mathrm{ng} / \mathrm{spot}$ for TRIA.

Hydrogen peroxide-induced degradation, Neutral Hydrolysis, Sunlight and Dry heat degradation

To the step one, $1.0 \mathrm{~mL}$ of $3 \%$ Hydrogen peroxide (for Oxidative degradation) and $1.0 \mathrm{~mL}$ of water (for Hydrolytic degradation) were added in two separate volumetric flasks and dissolved the content and diluted with methanol to make up the volume and solution so prepared were placed at room temperature for $8 \mathrm{hrs}$ and refluxed at $80^{\circ} \mathrm{C}$ for $8 \mathrm{hrs}$ respectively . Additionally, the drug powder in step one was exposed to dry heat at $80^{\circ} \mathrm{C}$ for $8 \mathrm{hrs}$ and at sunlight for $8 \mathrm{hrs}$.

The mixtures were allowed to cool and made up to the mark with the diluent. $1.0 \mathrm{~mL}$ of this solution was then transferred to a $10 \mathrm{~mL}$ volumetric flask and the volume was made up with methanol. From this solution $2 \times 50 \mu \mathrm{L}$ samples were plotted in the form of bands by using linomat IV, applicator on precoated silica gel aluminium plate 60GF-254 to get 1000 ng $\operatorname{spot}^{-1}$ for TRIA. 
<smiles>C[C@]12C[C@H](O)[C@@]3(F)[C@@H](CCC4=CC(=O)C=C[C@@]43C)[C@@H]1C[C@@H](O)[C@]2(O)C(=O)CO</smiles>

Figure 1: Structure of Triamcinalone.

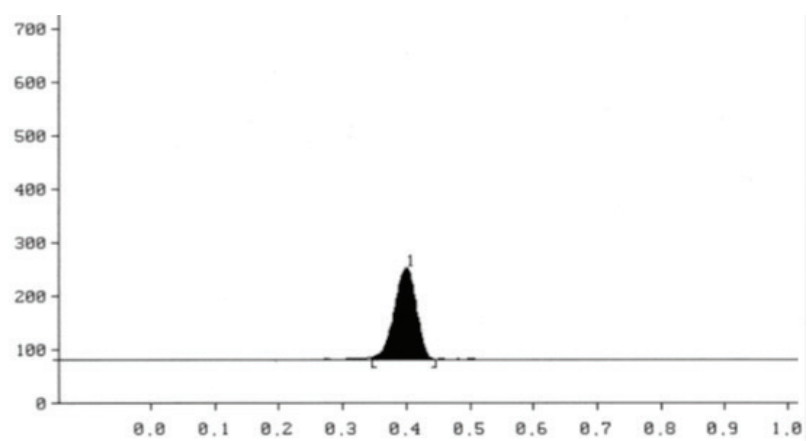

Figure 2: A typical HPTLC chromatogram ofTRIA (1000 ng spot -1) $(\mathrm{Rf}=0.38 \pm 0.02)$.

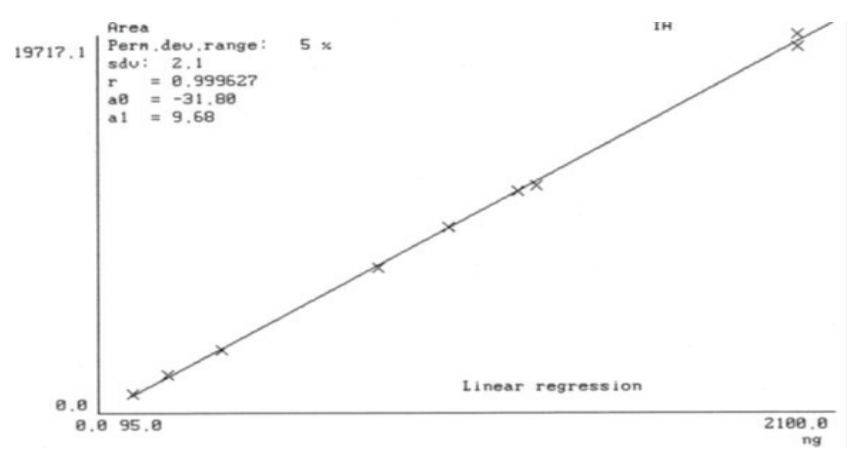

Figure 5: Calibration curve of TRIA.

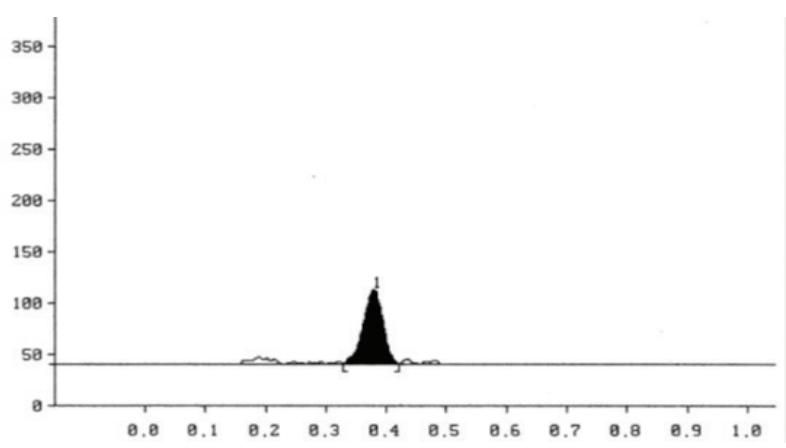

Figure 3: A HPTLC chromatogram of TRIA at the LOQ (100 ng spot $\left.{ }^{-1}\right)$.

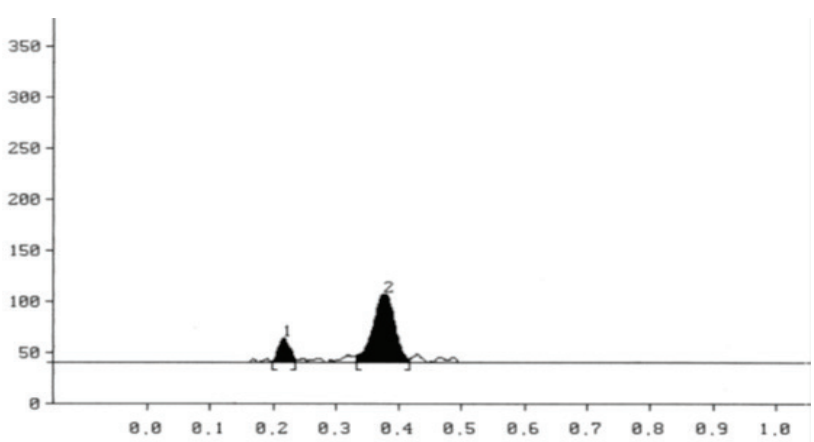

Figure 4: HPTLC chromatogram of alkali degraded TRIA.

Table 1: Concentration of standards and corresponding area of TRIA

\begin{tabular}{cc}
\hline $\begin{array}{c}\text { Conc. } \\
(\mu \mathrm{g} / \mathrm{mL})\end{array}$ & Area \\
\hline 100 & 1017.4 \\
200 & 2010.1 \\
350 & 3290.4 \\
800 & 7578.0 \\
1000 & 9723.0 \\
1200 & 11580.3 \\
1250 & 11905.1 \\
2000 & 19717.1 \\
\hline
\end{tabular}

Table 2: Intra- and inter-day precision of HPTLC method

\begin{tabular}{ccccccc}
\hline \multirow{2}{*}{$\begin{array}{c}\text { Amount } \\
\text { (ng/spot) }\end{array}$} & \multicolumn{2}{c}{ Intra-day precision a) } & \multicolumn{4}{c}{ Inter-day precision a) } \\
\cline { 2 - 7 } & Mean area & S.D. & \%RSD & Mean area & S.D. & \%RSD \\
\hline 1000 & 9675.8 & 45.45 & 0.47 & 9844.5 & 30.73 & 0.31 \\
\hline
\end{tabular}

\section{RESULTS AND DISCUSSION}

\section{Method development}

Selection of optimum mobile phase

HPTLC procedure was optimized with a view to developing a stability indicating assay method. Three solvent ratios were selected as to optimize the best among them. Initially, Toluene: ethyl acetate $(33: 67 \mathrm{v} / \mathrm{v})$ gave good resolution with $\mathrm{R}_{\mathrm{f}}$ value of 0.38 for TRIA but typical peak nature was missing. Finally, the mobile phase consisting of toluene : ethyl acetate : ammonia solution (33:67:0.1 v/v \%) gave a sharp and well defined peak at $R_{f}$ value of 0.38 (Figure 2). Well-defined spots were obtained when the chamber was saturated with the mobile phase for $30 \mathrm{~min}$ at room temperature.

\section{Validation of the method Calibration curves}

The linear regression data for the calibration curves showed a good linear relationship over the concentration range 100-2000 ng spot ${ }^{-1}$ with 
Table 3: Robustness of the method

\begin{tabular}{ccc}
\hline Parameter & S.D.of peak area & \%RSD \\
\hline $\begin{array}{c}\text { Mobile phase composition } \\
\text { Toluene:Ethylacetate:Ammonia solution (31:69:0.1) }\end{array}$ & 1.552 & 0.156 \\
Mobile phase composition & 1.012 & 0.101 \\
Toluene:Ethylacetate:Ammonia solution (35:65:0.1) & & 0.108 \\
Chamber saturation time $(25 \mathrm{~min})$ & 1.071 & 0.121 \\
Chamber saturation time $(35 \mathrm{~min})$ & 1.204 & 0.115 \\
Temperature for activation of plates $\left(100^{\circ} \mathrm{C}\right)$ & 1.148 & 0.125 \\
Temperature for activation of plates & 1.252 & \\
$\left(120^{\circ} \mathrm{C}\right)$
\end{tabular}

Table 4: Recovery studies a)

\begin{tabular}{|c|c|c|c|c|c|}
\hline $\begin{array}{c}\text { Recovery level } \\
(\%)\end{array}$ & $\begin{array}{c}\text { Amt of drug } \\
\text { added } \\
\text { (ng/ spot) }\end{array}$ & $\begin{array}{l}\text { Amount of drug } \\
\text { found } \\
\text { (ng/spot) }\end{array}$ & $\begin{array}{c}\text { Percentage } \\
\text { recovery }\end{array}$ & Mean \% recovery & $\%$ RSD \\
\hline \multirow{5}{*}{80} & 800.000 & 797.670 & 99.71 & \multirow{3}{*}{100.87} & \multirow{3}{*}{1.24} \\
\hline & 800.000 & 805.512 & 100.69 & & \\
\hline & 800.000 & 817.606 & 102.20 & & \\
\hline & 1000.000 & 990.851 & 99.09 & & \\
\hline & 1000.000 & 992.806 & 99.28 & 98.92 & 0.46 \\
\hline \multirow[t]{3}{*}{100} & 1000.000 & 984.086 & 98.41 & & \\
\hline & 1200.000 & 1184.615 & 98.72 & \multirow{3}{*}{98.59} & \multirow{3}{*}{0.36} \\
\hline & 1200.000 & 1178.243 & 98.19 & & \\
\hline 120 & 1200.000 & 1186.308 & 98.86 & & \\
\hline
\end{tabular}

Mean Recovery $($ Mean \pm S.D. $)=99.46 \pm 1.23$

a) $(n=9)$

Table 5: Summary of validation parameters

\begin{tabular}{cc}
\hline Parameter & Data \\
\hline Linearity range $(\mathrm{ng}$ spot-1) & $100-2000$ \\
Correlation coefficient & 0.9996 \\
Limit of detection (ng spot-1) & 33.0 \\
Limit of quantitation (ng spot-1) & 100 \\
Percent recovery $(\mathrm{n}=9)$ & $99.46 \pm 1.23$ \\
Precision $(\mathrm{RSD} \%$.) & 0.35 \\
Repeatability of application $(\mathrm{n}=6)$ & 0.06 \\
Repeatability of measurement $(\mathrm{n}=6)$ & 0.41 \\
Inter-day $(\mathrm{n}=6)$ & 0.61 \\
Intra-day $(\mathrm{n}=6)$ & Robust \\
Robustness & Specific \\
Specificity &
\end{tabular}

Table 6: Analysis of TRIA sterile injectable suspension (1000.00 ng spot $^{-1}$ )

\begin{tabular}{|c|c|c|c|}
\hline Pharmaceutical formulation & $\begin{array}{c}\text { Actual concentration of TRIA } \\
\left.\text { (ng spot }{ }^{-1}\right)\end{array}$ & $\begin{array}{l}\text { Amount of TRIA calculated } \\
\left.\text { (ng spot }{ }^{-1}\right)\end{array}$ & $\begin{array}{c}\% \text { TRIA } \\
(\text { mean } \pm S D) \\
(n=3)\end{array}$ \\
\hline $\begin{array}{l}\text { TRIA Sterile injectable } \\
\text { suspension }\end{array}$ & 1000.000 & 991.453 & $99.15 \pm 0.41$ \\
\hline
\end{tabular}


Table 7: Forced degradation of TRIA

\begin{tabular}{cc}
\hline Stress Condition & \% Degradation \pm S.D \\
\hline Base(0.01 N NaOH) @ RT for 2 Hour & $22.67 \pm 0.16$ \\
Acid $(0.1 \mathrm{~N} \mathrm{HCl}) @ 80^{\circ} \mathrm{C}$ for 8 Hour reflux & $6.98 \pm 0.15$ \\
Oxidative $\left(3 \% \mathrm{H}_{2} \mathrm{O}_{2}\right)$ RT for 8 Hour & $4.49 \pm 0.13$ \\
Thermal $\left(80^{\circ} \mathrm{C}\right)$ for 8 Hour & $4.90 \pm 0.10$ \\
Neutral (water)@ $80^{\circ} \mathrm{C}$ for 8 Hour & $4.27 \pm 0.04$ \\
Sunlight for 8 Hour & $9.23 \pm 0.11$ \\
\hline
\end{tabular}

respect to peak area. Results were tabulated in Table 1. The regressioncoefficient (r) was found to be 0.9996 (Figure 5) which is within the acceptance criteria limit of $\geq 0.99$.

\section{Precision}

The repeatability of sample application and measurement of peak area were expressed in the terms of \% RSD and the results are depicted in Table 2, which revealed intra-day and inter-day variation of TRIA at a concentration level of $1000 \mathrm{ng} \mathrm{spot}^{-1}$.

\section{Robustness of the method}

The standard deviation of peak areas was calculated for each parameter and \%R.S.D was found to be less than $2 \%$. The low values of $\%$ RSD values as shown in Table 3 indicated robustness of the method.

\section{$\angle O D$ and $L O Q$}

The signal-to-noise ratio 3:1 and 10:1 were considered as LOD and LOQ respectively. The LOD and LOQ were found to be 33.0 and $100.0 \mathrm{ng}$ spot $^{1}$, respectively. Chromatogram at LOQ of TRIA is given in Figure 3.

\section{Specificity}

The developed method was used for the estimation of TRIA in bulk drug and pharmaceutical dosage form. The excipients did not interfere in the estimation. Interferences from the formulation and degradants were absent. These results indicated the specificity of the method.

\section{Recovery studies (Accuracy)}

The proposed method when used for extraction and subsequent estimation of TRIA from pharmaceutical dosage forms after spiking with 80, 100 and $120 \%$ of additional drug afforded mean recovery of $99.46 \pm 1.23$ as listed in Table 4 . The data of summary of validation parameters are listed in Table 5.

\section{Analysis of prepared formulation}

A single spot of $\mathrm{R}_{\mathrm{f}} 0.38$ was observed in chromatogram of the TRIA samples extracted from sterile injectable suspension. There was no inter- ference from the excipients commonly present in the formulation. The average TRIA content was found to be $99.15 \% \pm$ SD of 0.41 and listed in Table 6. Therefore it may be inferred that degradation of TRIA had not occurred in the formulation which were analysed by this method. The low SD value indicated the suitability of this method for routine analysis of TRIA in pharmaceutical dosage forms.

\section{Stability- indicating property}

The chromatogram of samples degraded with acid, base, hydrogen peroxide, neutral, sunlight and heat showed well separated spots of pure TRIA as well as some additional peaks at different $R_{f}$ values. The spots of degraded products were well resolved from the drug spot as shown in Figure 4. Percentage degradation was calculated and listed in Table 7.

\section{CONCLUSION}

The new HPTLC method is specific, and sensitive for the estimation of TRIA. Statistical analysis proves the method is reproducible and selective for analysis of TRIA. The proposed method is less time consuming and it can be used for routine Quality control test and stability studies of TRIA in Bulk drug and in its pharmaceutical dosage form. As the method separates the drug from its degradation products, it can be employed as a stability indicating one.

\section{ACKNOWLEDGEMENT}

Thankful to Manipal University, Pharmaceutical quality assurance lab for instrumentation support. Thankful to DST-FIST lab for instrumentation support.

\section{CONFLICT OF INTEREST}

None.

\section{REFERENCES}

1. ICH, Q1A (R2) Stability Testing of New Drug Substances and Products, International Conference on Harmonization, Geneva, October, 1993.

2. Kohen F, Linder HR, Gilad S and Steroid. J Bio Chem. 1983;19:413.

3. Bonte F, Pinguet P, Chevalier JM, Meybeek J. Chromatography. 1995;664:311.

4. Nores GA, Mizutamari RK, Kremer DM and Chromatography J. 1994;68(12):155.

5. Datta K, Das SK, AOAC Int J. 1994;77(6):1435.

6. Tammilehto S, Salomies H, Torniainen J, Planar J. Chromatography. Mod. TLC. 1994;7:368

7. Karen M. Alsante, Akemi Anod and Yoshiko Tsuda, Advanced Drug Delivery Reviews. 2007:59(1):29.

8. Validation of analytical procedures: Text and Methodology Q2 A (R1): ICH Harmonized Tripartite Guideline, Geneva, November, 2007.

9. Validation of analytical procedures: Text and Methodology Q2 B (R1): ICH Harmonized Tripartite Guideline, Geneva, November, 2007.

10. ICH Guidance on Analytical Method Validation, in: Proceedings of The International Convention on Quality for the Pharmaceutical Industry, Toronto, Canada, 
PICTORIAL ABSTRACT

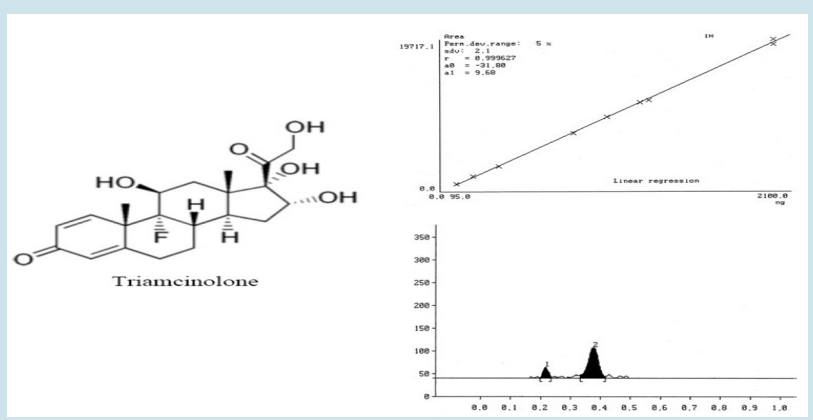

\section{SUMMARY}

- A sensitive, accurate, precise and stability indicating HPTLC method was developed and validated for analysis of triamcinalone acetonide (TRIA) in bulk drug and sterile injectable suspension

- The solvent system consisted of Toluene: ethyl acetate: ammonia solution (33:67:0.1\%v/v). This system was found to give compact bands for TRIA (Rf value $0.38 \pm 0.02$ )

- The linear regression date for the calibration plots showed good linear relationship with correlation coefficient $0.9996 \pm / 0.001$ in the concentration range of 100.0-2000.0 ng spot-1.

- As the method could effectively separate the drug from its degradation products, it can be employed as a routine stability indicating assay method.

\section{ABOUT AUTHORS}

Muddukrishna B.S.: Is Assistant Professor-Senior scale in Department of Pharmaceutical Quality Assurance, Manipal College of Pharmaceutical Sciences, Manipal University. He teaches pharmaceutical analysis to undergraduate students and pharmaceutical quality assurance and management to post graduate students of Pharmacy.

He has $16+$ years of total experience in academics, Research \& Development, Laboratory Operations \& Quality Assurance in an organization of high repute.

He has published several papers in journals of high repute and have presented papers in national and international conference.

Girish Pai K.: Is Assistant Professor-Selection Grade in Department of Pharmaceutics, Manipal College of Pharmaceutical Sciences, Manipal University. He teaches pharmaceutics, pharmaceutical technology, industrial pharmacy to undergraduate students and advanced industrial pharmacy, process validations, training \& development and stability studies as per ICH guidelines to post graduate students of Pharmacy.

He has 16 years of experience in Research \& Development, Validations \& Quality Assurance in organizations of high repute.

He has published several papers in journals of high repute and have presented papers in national and international conferences. 